\title{
FISSURAS DECOLONIAIS: TRAUMA COLONIAL, FILOSOFIAS E ENSINO
}

Joana Tolentino*

\begin{abstract}
Resumo: Esse texto propõe uma reflexão acerca das feridas da colonialidade, especialmente o racismo, o sexismo e o complexo de inferioridade, e suas marcas na concepção hegemônica ocidental de filosofia, seu cânone, suas práticas e ensino, foco último da investigação nesse escrito. O objetivo, após o reconhecimento deste modelo hegemônico e sua crítica, é apresentar outras possibilidades de conceber a atividade filosófica, seu cânone e sua prática educativa, a partir da criação de fissuras decoloniais. Concepções de filosofia e ensino baseadas nos princípios da democracia, diversidade, horizontalidade, criatividade, que promovam a equidade étnica, de gênero, sexualidade, entre os seres em geral, pessoas, territórios, culturas.
\end{abstract}

Palavras-chave: Decolonialidade; Ensino de Filosofia; Trauma Colonial; Racismo/Sexismo Epistêmico.

Resúmen: Este texto propone una reflexión acerca de las heridas de La colonialidad, especialmente el racismo, el sexismo, el complejo de inferioridad, y sus huellas en La concepción hegemónica occidental de filosofía, su canon, prácticas y enseñanza, enfoque final de La investigación en esa escritura. Nuestro objetivo, luego del reconocimiento de este modelo hegemónico y su crítica, es presentar otras posibilidades de concebir la actividad filosófica, su cánon y su práctica educativa, a partir de la creación de fisuras decoloniales. Concepciones de filosofía y enseñanza basadas em los principios de democracia, diversidad, horizontalidad, creatividad, que promuevan La equidad étnica, de género, sexualidad, entre los seres, personas, territorios, culturas.

Palabras claves: Decolonialidad; Enseñanza de Filosofía; Trauma Colonial; Racismo/Sexismo Epistémico.

\section{Introdução}

Esse texto tematiza as implicações para o ensino de filosofia da colonialidade presente na compreensão ocidental hegemônica de filosofia, seu cânone e as práticas que a sustentam, e o quanto isso afeta os espaços de produção de conhecimento onde a filosofia está presente. Iniciaremos com a identificação de algumas marcas da colonialidade no cânone filosófico e nas práticas filosóficas, em especial de ensino, refletindo sobre as deformações causadas pelo trauma colonial

\footnotetext{
* Professora do Departamento de Filosofia do Colégio Pedro II, membra do grupo de pesquisa Corpoder filosofias decoloniais: corpos, poderes e saberes e do GT Filosofar e Ensinar a Filosofar (ANPOF). Doutora em filosofia pela Universidade Federal do Rio de Janeiro (UFRJ). E-mail: joana.tolentino@gmail.com.
}

na concepção de filosofia que experienciamos, suas práticas, como também nos espaços ensinantes, em especial a escola e a universidade. O objetivo é problematizar esse simbólico da filosofia presente em sua versão hegemônica ocidental, que predomina no imaginário coletivo e nas instituições de ensino, tentando identificar os contornos da concepção de mundo que ela fundamenta $e$ os traços dos processos de subjetivação padronizados e auto-alienados que fomenta. A partir do reconhecimento das feridas estruturais que esses padrões da colonialidade reforçam, em especial o racismo e o sexismo, a proposta é criar fissuras, através das quais seja possível abrir fendas para uma educação democrática, inclusiva, que reconheça $e$

TOLENTINO, Joana. Fissuras decoloniais: trauma colonial, filosofias e ensino. Revista Sul-Americana de Filosofia e Educação. Número 34: nov. 2020 - abril 2021, p. 110-126. DOI: https://doi.org/10.26512/resafe.v2i34.35135 
valorize a diversidade, fomentando a equidade e o respeito à diferença.

O modelo hegemônico que predomina na filosofia ocidental, suas práticas e ensino é nutrido, conscientemente ou não, por valores que se expressam na ética, na epistemologia, na estética, na política, marcando a própria ontologia. Vivemos sob a égide de uma filosofia ocidental que se requer hegemônica (alguns até podem estranhar a expressão "filosofia ocidental" como se fosse um pleonasmo), associada simbolicamente a um cânone que é excludente - norteeurocentrado, branco, heteropatriarcal, androcêntrico. A colonialidade também impõe sua marca nas práticas filosóficas (de escrita e publicação, acadêmicas, de ensino, pesquisa, orientação, tradução, extensão), o que se reflete principalmente no sexismo e no racismo, pilares da ferida colonial, evidenciados nos referenciais teóricos adotados (e nos invisibilizados), como também no acesso aos espaços de produção de conhecimento (ARAÚJO, 2019). Poderia haver o questionamento de que essas marcas da colonialidade não são uma exclusividade da filosofia. Pensamos que esse questionamento nos serve enquanto ampliação de horizonte, para avaliarmos como ainda mais fundamental o projeto de descolonização da filosofia, a fim de que este possa, por reverberação, contribuir para a superação das feridas coloniais e suas marcas em outros cânones e saberes, em outros espaços institucionais. No entanto, esse questionamento não pode servir para nos eximir de realizar a auto-crítica filosófica, afinal não está a filosofia associada à crítica, quase que metodológica, epistêmica e ontologicamente? Não seria a auto-crítica ele- mento fundamental, se não pressuposto, de toda criticidade efetiva?

Pesquisar os atravessamentos da colonialidade nos saberes e práticas filosóficas parece-nos mais do que pertinente no contexto de reformas no ensino médio, que impactam o ensino de filosofia, na educação básica e na universidade, entrelaçadas a partir da formação docente, como também nesse momento de acirramento das cisões sociais. Vivemos numa sociedade cindida pelo trauma colonial, que é ainda latente e renovadamente vivido no cotidiano das corporalidades que foram subalternizadas, como as corporalidades não-brancas, as mulheres, as populações pertencentes às classes mais empobrecidas, lgbtqi+, causando profundos impactos sociais, culturais, epistêmicos, estéticos, econômicos, psicológicos. O quanto o ensino de filosofia pode contribuir para o enfrentamento e superação dessas opressões, e não para o seu acirramento, é o que está em jogo neste escrito.

O caminho adotado neste trabalho são as escavações (DONINI, 2020) sobre os traços borrados, mas cujos vestígios podem ser alinhavados e tecidos, presentes no ideário do que se entende por filosofia, seus conhecimentos, suas práticas discursivas e educativas, atingindo também os espaços de ensino $e$ aprendizagem em que a filosofia se faz presente, seguindo os rastros da colonialidade. Entendemos o enfrentamento do trauma colonial como pressuposto para que possamos ser exitosos na promoção de mudanças efetivas no ensino da filosofia e, desde atuações localizadas, com reverberações no ensino das humanidades e no sistema de ensino. A ferida colonial, que tem como marcas principais o racismo e o sexismo, 
nunca foi devidamente reconhecida, reparada e curada, ao contrário, está arraigada na colonialidade, enraizada no colonialismo interno e, uma vez disseminada pela globalização, só aprofundou as cisões no tecido social - mundial e local. Acreditamos nas ações micropolíticas que, em teia, têm potencial para provocar fissuras nas estruturas, abalando-as por dentro, até que as pequenas, mas múltiplas fissuras, aqui e ali, provoquem fendas, que, multiplicizando as rupturas, são capazes de causar erosões perenes, alterando o estado das coisas. Nossa estratégia é tensionar a colonialidade da filosofia $e$ de seu ensino, criando fissuras decoloniais que propiciem transformações no fazer filosófico e, por reverberação, em outros cânones e práticas.

\section{Colonialidade e os espaços de produção de conhecimento}

O fato colonial se perpetua na atualidade, com o fenômeno da globalização, através do colonialismo interno e da colonialidade política, econômica, epistêmica, ontológica, aprofundando o trauma colonial. Que cosmovisão de mundo e existência é nutrida com a concepção e o simbólico de filosofia que se compartilha no mundo ocidental hoje? Quais processos de subjetivação o ensino dessa concepção de filosofia e suas metodologias fomentam? Um modelo padronizado, norte-eurocentrado, que perpetua a colonialidade nas exclusões étnico-raciais, de gênero, sexualidade, geográficas, desqualificando, silenciando e invisibilizando a maioria das culturas, povos, seres, territórios, epistemes, na tentativa de borrar a diversidade constitutiva da humanidade, enquanto parte da natureza em sua multiplicidade de seres.

\begin{abstract}
Em todas as sociedades onde a colonização implicou a destruição da estrutura societal, a população colonizada foi despojada dos seus saberes intelectuais e dos seus meios de expressão (...). A longo prazo, em todo o mundo eurocentrado foi-se impondo a hegemonia do modo eurocêntrico de percepção e produção de conhecimento e numa parte muito ampla da população mundial o próprio imaginário foi, demonstradamente, colonizado (QUIJANO, 2010, p.124).
\end{abstract}

Quais são as implicações nocivas desse imaginário colonizado para a vida, a convivência, a educação? Em especial, nos questionamos quais os impactos na filosofia e suas práticas educativas desse modelo civilizatório que marca fortemente os sistemas de ensino, como braços do Estado. Um modelo humanista, antropocêntrico, que se contrapõe aos saberes originários, ancestrais, classificando-os como "outros", porque diferem da sua mesmidade, considerando-os bárbaros, selvagens, primitivos (SODRÉ, 2017). Esta desqualificação justificaria sua subalternização, em classificações como marginais, subdesenvolvidos, periféricos, responsáveis por "atrasos" no processo de desenvolvimento, supostamente único e ascendente, em relação às eternas metrópoles - os países centrais, no interior do processo de mundialização econômica, midiática, do consumo. Globalização associada à apropriação cultural, à destruição da diversidade dos seres na natureza, das culturas na humanidade, que aparecem cindidas nesse modelo, reafirmando circularmente a lógica da colonialidade do saber, do poder e do ser (QUIJANO, 2010). 
Sabemos, tanto por parte das teorias pedagógicas quanto pelas análises sociológicas e filosóficas, o quanto os espaços institucionais de ensino, em especial a escola e a universidade, podem ser opressores e excludentes para muitos corpos que, entramados nesses espaços, tecem subjetividades não hegemônicas. Escola que serve para guardar corpos que foram subalternizados e estão submetidos à constante vigilância e controle, com fins de padronização, normalização, disciplinarização. Não é por mero acaso que há uma linguagem comum, repleta de palavras e expressões usadas tanto na escola, quanto nas prisões: sistema de ensino e sistema prisional; grade, palavra usada tanto para designar os ferros que isolam as celas, quanto para se referir à grade horária ou grade curricular - expressões caras ao universo escolar; geografia, história, matemática são consideradas disciplinas - mas, afinal, elas visam ensinar ou disciplinar? Como tematizou Michel Foucault (1987), as escolas são o primeiro estágio para a normalização dos corpos, caso esse estágio fracasse, o destino será a prisão ou o hospício.

A escola e o ensino associados a esse modelo, cuja gênese remete aos sistemas de ensino europeus, foram instaurados a partir da modernidade - no auge do projeto colonial que até hoje deixa marcas profundas. Os sistemas de ensino europeus já foram problemáticos desde seu berço, uma vez que visavam à padronização da classe trabalhadora, no sentido de facilitar sua inserção no esquema de dominação, controle e exploração. Mas, com a racialização, a sexualização, a genderização que geraram a estratificação dos corpos no interior do projeto colonial, adquiriram requintes de crueldade nas colô- nias, onde a empresa colonial operou um verdadeiro genocídio dos povos originários que desde há muito habitavam estes territórios e promoveu a exploração desumana de africanas/os que para cá vieram submetidos ao tráfico e à escravização, sua e de seus descendentes.

Aos sobreviventes foi aplicada uma política de apagão existencial dessas subjetividades, num processo de desontologização profunda - com efeitos nos campos epistêmico, ético, estético, projeto de exclusão e desigualdade que perdura ainda na atualidade. Primeiramente, com a interdição de frequentar os espaços formais reconhecidos pela produção de saberes legitimados, como a escola e a universidade. Posteriormente às interdições, as oportunidades de inserção social que surgiam restringiram-se, quando muito, a espaços extremamente precários de educação, marcados pela falta de infraestrutura. Na história da terra brasilis, no entanto, é importante frisar que essas populações sempre existiram e resistiram, compondo parcela expressiva do povo brasileiro e representando muito de nossa cultura. Após a interdição, a marca passou a ser da não inclusão da representação de suas corporalidades nas matrizes epistêmicas de ensino - nos referenciais teóricos citados e referendados através dos cânones, devido ao racismo e o sexismo epistêmicos, como também nas metodologias e práticas adotadas, hierarquizantes.

A diversidade de nosso povo traz para a Pedagogia do Terreiro o desafio de gerar formação para as pessoas que são vitimadas pela exclusão social, pelo racismo, pelo sexismo e que, muitas vezes, não encontram 
identidade com outras metodologias $e$ pedagogias que negam as suas experiências $e$ as separa e segrega (KAFURENGÁ, 2017, p.31).

Foi nesse modo epistemicida baseado em práticas colonizadoras excludentes de interdição, silenciamento e invisibilização, que, no interior desse sistema de ensino fundamentado na segregação, certas experiências e modos de ser e viver foram considerados "outros" e negados, disseminando o projeto de padronização das subjetividades $e$, por conseguinte, da sociedade como um todo, baseado no modelo hegemônico eurocentrado, hierarquizado, genderizado, racializado. A pedagogia do terreiro, assim como outras iniciativas baseadas no diálogo intercultural entre as distintas matrizes culturais que compõem a cultura brasileira, atua visando incluir as corporalidades historicamente subalternizadas nos processos de ensino $e$ aprendizagem, a partir de outras estratégias.

\section{Trauma colonial}

Viver numa sociedade que foi colonizada é carregar o traço da colonialidade deformando o simbólico e o inconsciente coletivo, como um nó traumático que desafina os fluxos, os movimentos, as relações, afetando os processos de subjetivação, corrompendo o tecido social. O trauma colonial possui pilares estrutural, histórico, cotidiano, institucional, por onde está enraizado o sexismo, o racismo (KILOMBA, 2019). O colonialismo interno (DE OTO; CATELLI, 2018) é um dos pés de sustentação da colonialidade, especialmente no interior dos exterritórios coloniais, reproduzindo infinitamente as estratificações e opressões na excolônia, com classificações raciais, de gêne- ro, sexualidade, classistas, geográficas, etárias que afetam todas as esferas da vida. Mas é em torno, principalmente, das categorias de raça, gênero, trabalho e sexualidade, que as relações de opressão/exploração/conflito se articulam no capitalismo hegemônico, desde a modernidade. Trata-se da perpetuação da “(...) lógica opressiva da modernidade colonial, [com] seu uso de dicotomias hierárquicas e de lógica categorial" (LUGONES, 2014, p.935), opondo homens e mulheres, brancos e não brancos, pessoas heteronormativas e lgbtai + , ricos e pobres, elite e povo. Essas hierarquizações realizam um espelhamento das dicotomias centrais, funcionando como reflexos da cisão ontológica originária entre o ser e o não ser: humano/cultura x natureza, civilizados x bárbaros, desenvolvidos $\mathrm{x}$ primitivos, demarcando a zona do ser, à qual o polo primeiro está sempre associado, e a zona do não-ser (FANON, 2008), que comporta as corporalidades marginalizadas e, em última instância, desontologizadas, no polo desvalorizado, identificado com o "outro", o subalternizado.

O passado colonial foi 'memorizado' no sentido em que "não foi esquecido'. Às vezes, preferimos não lembrar, mas, na verdade, não se pode esquecer. A teoria da memória de Freud é, na realidade, uma teoria do esquecimento. Ela pressupõe que todas as experiências, ou pelo menos todas as experiências significativas, são registradas, mas que algumas ficam indisponíveis para a consciência como resultado da repressão e para diminuir a ansiedade. Já outras, no entanto, como resultado do trauma, permanecem presentes de forma espantosa. Não se pode simplesmente esquecer e não se pode 
evitar lembrar" (KILOMBA, 2019, p.213).

Os elementos centrais do trauma, como nos ensina Grada Kilomba, são: i) o choque violento, que traz uma experiência inesperada ou a recriação do elemento surpresa que a subjetividade é incapaz de assimilar; ii) a ruptura ou separação que instaura subcategorias da humanidade; iii) a atemporalidade, que mantém a presença da ferida, revivendo no presente um evento que ocorreu no passado ou vice-versa.

A situação presente, ainda que pós colonial, traz em si rastros inapagáveis do fato colonial nos territórios que se mantém à margem no capitalismo globalizado. Esse trauma tem distintas ramificações que atingem a todos e todas, ainda que de diferentes maneiras. No traçado cartográfico da geopolítica do ser e do conhecimento (MALDONADO-TORRES, 2008), nas ex-colônias, localizadas principalmente na América Latina e no Caribe, na África e na Oceania, ninguém ocupa efetiva e ontologicamente a zona do ser: todos trazem, em distintas intensidades, a marca da diferenciação em relação ao modelo hegemônico ariano, androcêntrico, norte-centrado. Justamente por isso, tudo gira em torno da noção de privilégio (MEMMI, 2007), numa escala ascendente, com inúmeros estágios, em direção à maior proximidade ao padrão de branquitude, hetero-masculinidade, preferencialmente com um patronímio que comprove ascendência europeia. A partir disso, testemunhase a repetição análoga dos dispositivos de opressão, especialmente o racismo e o sexismo, nos países independentes, outrora colonizados, com requintes de crueldade $e$ despreocupação em relação aos impactos destrutivos na economia local, no meioambiente, na fragmentação social. Afinal, violência foi o modo como fomos constituídos enquanto povo e estariam enraizada em nossa identidade cultural o saque, a pilhagem, a escravização, o tráfico de seres humanos, bases da nossa colonização, evidenciados na violência continuada e revivida do racismo, da expropriação, do ecocídio, da homofobia, do feminicídio.

Separar para dominar era o lema do colonialista europeu moderno, aliando-se às elites locais que sempre se beneficiaram com a colonização e fazem qualquer negociata para perpetuar seus privilégios na colonialidade. Nesse jogo a elite colonial desempenha o papel de augusto que, na dupla de palhaços, funciona como "escada" para que o palhaço denominado branco se destaque, faça seu número, apareça. O palhaço com maior ocorrência nos palcos, ruas e picadeiros do Brasil, não à toa, é o augusto, o palhaço coadjuvante. Nada é aleatório nessa representação teatral: o branco foi assim denominado por inspiração de um clown de grande sucesso que, na Inglaterra do século XVIII, em plena modernidade colonial e suas teorias eugenistas e classificatórias, pintava seu rosto de branco intenso e usava roupas elegantes, fazendo alusão às classes abastadas. No jogo da cena, na arte, na palhaçaria, na ficção tudo é permitido, mas no mundo real o que salta aos olhos nesse jogo de subalternizações entre países e suas respectivas elites é a subserviência das classes dominantes coloniais à pilhagem das riquezas do território em que vivem, é seu entreguismo, sem se preocupar no quanto essa dependência econômica, estética, epistêmica afeta e destrói: os corpos, a natureza, os territórios. 
É a perpetuação de um padrão hegemônico hierárquico que causa o racismo e o sexismo epistêmico (GROSFOGEL, 2016) e, em última instância, o epistemicídio, uma vez que nega a essas corporalidades o estatuto de subjetividades produtoras de conhecimento (FANON, 2008).

O raciocínio da elite subalterna e colonizada parece ser de que, quanto mais exercem a servidão voluntária, mais se aproximam do tirano e poderão dele se beneficiar, na expectativa de conseguir, eles mesmos, exercer a tirania, gozando de pequenos autoritarismos nos espaços localizados de poder. Desse modo negam o quanto são desqualificados e desvalorizados pelo excolonialista, cegos na tentativa de ser o que não são, na busca subserviente de um pertencimento ontológico do qual, embora ignorem, também estão excluídos. No que se refere ao psiquismo isso se expressa no complexo de inferioridade ou, como nomeado no Brasil, no complexo de vira-lata, que é a patologia colonial da branquitude. Assim, certas corporalidades fazem de tudo para parecer mais brancas, mais ricas, mais escolarizadas na cultura, supostamente superior, europeia, mais fluentes em suas línguas, mais absortas em seus costumes.

Todo povo colonizado - isto é, todo povo no seio do qual nasceu um complexo de inferioridade devido ao sepultamento de sua originalidade cultural - toma posição diante da linguagem da nação civilizadora, isto é, da cultura metropolitana. Quanto mais assimilar os valores culturais da metrópole, mais o colonizado escapará da sua selva. (FANON, 2008, p.34).
Essa é a ilusão, denunciada por Fanon. Nos territórios coloniais, teoricamente independentes, a branquitude, impulsionada pelo complexo de inferioridade em relação ao ser metropolitano, ainda que no modo inconsciente do recalque e da negação (GONZALEZ, 2018), reproduz a mesma lógica de dominação colonial através das tiranias, agora localizadas, na manutenção de perversos processos de desontologização. Corpos marcados pela objetificação, através de processos de racialização e sexualização, tiveram seus saberes deslegitimados em processos que, quando não culminaram no genocídio de seus corpos, causaram o epistemicídio de suas corporalidades, não identificadas enquanto subjetividades produtoras de conhecimentos válidos (NOGUERA, 2005). Esses processos de colonialidade retroalimentam a ferida colonial, que purga, dói $e$ não pode ser simplesmente esquecida, apagada, ao contrário, precisa ser enfrentada $e$ superada coletivamente, pois chega a atingir o nível de provocar a auto-alienação das subjetividades, na tentativa do apagamento de si mesmas, como tentativa de ser aceita/o socialmente, identificando-se com o padrão hegemônico. Tentativa de apagamento de modos de ser $e$ viver afro-indígenoreferenciados, assim como tentativa de apagamento da feminilidade e de tudo que a ela esteve simbolicamente associado, enquanto construção social, histórica, cultural - corporeidade, sensibilidade, intuição, afetividade.

A herança da colonização acarreta marcas traumáticas que, individualmente, é possível que não tenhamos escolhido, mas que atravessam todo o tecido social, provocando rasgos, desintegrações, cisões, corrompendo-o de modo a comprometer sua 
tessitura, afetando decisivamente os processos de subjetivação. Esse trauma se mostra com muito mais intensidade do que poderíamos supor antes da realização das escavações (DONINI, 2020) que trazem à percepção, à superfície os rastros, os soterramentos da violência, da cisão, da desumanização, do racismo, do sexismo, outrora invisibilizados.

O racismo não é um problema pessoal, mas um problema branco estrutural $e$ institucional que pessoas negras experienciam. Esse é um acontecimento comum para negras e negros quando abordamos a questão do racismo: intimidação por um lado, patologização individual por outro. Ambas controlam mecanismos que impedem que o sujeito branco ouça verdades desconfortáveis, que, se levadas a sério, arruinariam seu poder (KILOMBA, 2019, p. 204).

Assim, é indispensável que haja uma repactuação na nossa sociedade, a fim de efetivamente conseguirmos desenvolvers um processo de cura e superação do trauma colonial e das marcas da colonialidade. Esse pacto vem sendo proposto pelo movimento negro (GOMES, 2017), indígena, de mulheres há décadas, mas essa situação não avançará enquanto não houver ruptura com os privilégios, pois é isso que mantém essa patologia social ativa. Assim, cabe aos privilegiados, à branquitude e às subjetividades hetero-masculinas, se engajarem nesse movimento, realizando a auto-crítica e se responsabilizando pela perpetuação dessas opressões que histórica e estruturalmente acarretam benefícios até hoje. A conseqüência primeira será a perda de privilégios - da garantia de postos de trabalho e de vagas nas instituições de ensino públicas de qualidade, das melhores remunerações, da monopolização de certos cargos de poder, dos discursos hegemônicos, da estética única que enaltece certos corpos. Esse processo de ruptura com uma história de usurpação exige abrir-mão do protagonismo, valorizando a diversidade, reconhecendo igualmente a todas/os como ser de direitos, de conhecimento, de beleza, colocando-se em postura de escuta e aprendizado de outras matrizes epistêmicas diversas.

No caminho da superação do racismo em nossa sociedade, a pesquisadora Maria Aparecida Bento nos brinda com a descrição do percurso para o desenvolvimento de uma identidade branca comprometida com a sua desconstrução e reinvenção. $\mathrm{O}$ primeiro estágio é o contato com a questão racial, que traz curiosidade primitiva e medo por tensionar a zona de conforto, após o abandono do mito da democracia racial que tanto nublou e ainda nubla o reconhecimento do racismo no Brasil; o segundo estágio, da desintegração, está associado à culpa, vergonha e até raiva por sua condição privilegiada, à revelia de suas escolhas; no terceiro estágio, da reintegração, ocorre a recusa do que já foi aprendido numa tentativa de retrocesso, de retorno à zona de conforto, transferindo ao outro a raiva que sente de si mesmo com a responsabilização pela violência estrutural; se a pessoa consegue sair desse estágio, no qual não é incomum haver uma paralisia, chega à última etapa, que é de imersão/emersão, quando há estudo e pesquisa na busca pela constituição de uma branquitude antirracista, culminando na autonomia, estágio final, quando há a afirmação de mo- 
dos não racistas de ser branco $e$ atuar no mundo (BENTO, 2008, p.17-18).

A superação da ferida colonial só ocorrerá com seu enfrentamento e tentativas de escamotear o racismo e o sexismo estruturais, institucionais, cotidianos, em nada contribuem para esse objetivo. Muito se pode aprender em como se engajar também com o movimento feminista, lgbtqi+, de trabalhadoras/es rurais, com os povos originários, aprendendo a provocar fissuras que contribuam para a ruína do trauma colonial, para o seu enterro definitivo e a necessária vivência de seu luto adequadamente.

\section{Auto-crítica filosófica}

As marcas da colonialidade no cânone filosófico e nas práticas filosóficas fundamentam-se nos mesmos pilares do racismo aos povos originários, à população afrodiaspórica, no sexismo, expresso tanto no machismo e na misoginia, quanto na lgbtqi+fobia, constituindo-se enquanto microcosmos do trauma colonial, com pés de apoio micropolíticos que o sustém. Seus traços são evidentes nas práticas filosóficas de escrita pouco criativas, devido ao complexo de inferioridade que se expressa na autoalienação do/a brasileiro/a, do/a latinoamericano/a que vê a si mesmo como subjetividade filosófica subalterna; no ensino conteudista, histórico, excessivamente especializado; nas relações hierarquizadas e subservientes entre docentes e discentes, orientadores $e$ orientandos; no eurocentrismo do cânone filosófico, também marcado pelo racismo e pelo sexismo epistêmicos. As corporalidades que lecionam, pesquisam, questionam, refletem e escrevem filosofia nos trópicos, o que fazem, afinal, se não filosofia?
Realizar o debate e fazer a desconstrução desse modelo de ensino de filosofia, $e$ de educação, em última instância, é mais do que necessário nesse momento de reformulação do sistema de ensino, com a BNCC alterando a educação básica, especialmente o ensino médio, etapa na qual a filosofia se faz presente e que está sendo radicalmente modificada com a lei 13.415/17. É também urgente porque vivemos tempos sombrios, em que mais do que nunca precisamos defender a democracia, a equidade de direitos e, para a sua consolidação e manutenção, uma educação laica, pública, gratuita, de qualidade, para todas e todos, que fomente e seja sustentáculo da convivência democrática. Afinal, Albert Memmi já nos alertava que "o colonialismo é uma variação do fascismo" (2007, p.100).

Infelizmente, as escolas e universidades, historicamente, têm estado a serviço desse projeto excludente - em seus currículos, estrutura e estratégias de ensino, na segregação de certas corporalidades dos e nos espaços de educação. Nossa herança prática mais imediata para o ensino da filosofia na educação básica, mas poderíamos afirmar da área de humanidades como um todo, em especial na fase final do ensino médio, é a cópia mal adaptada do modus operandi universitário, que já tende a ser, em si, uma reprodução da pós-graduação e sua ênfase na especialização. Enquanto docentes de filosofia (mas também de história, geografia, sociologia) ensinamos conhecimentos que estão associados a cânones nortecentrados, heteropatriarcais, brancos, que excluem de seus simbólicos as corporalidades com as quais estudantes, e também docentes, se identificam em seus processos de subjetiva- 
ção (como, por ex., mulheres e pessoas nãobrancas, maioria da população brasileira), que estão latentes nas juventudes que atuam nas escolas de ensino médio e nas graduações universitárias. Desse modo, promovemos e acirramos a auto-alienação $e$ as subalternizações, tanto no ensino e na aprendizagem, nas escolas e universidades, quanto na escrita e publicação de textos, na organização de eventos, nos concursos. Nestes espaços e referenciais teóricos, o ensino da filosofia e das humanidades é monolítico, não apresenta a diversidade, é colonizado $e$, com isso, não fomenta a equidade de direitos e a convivência democrática, função última das instituições de ensino, em seu aspecto ético de socialização e convivência com a diferença, de grande relevância.

Por isso, no empenho político de uma descolonização ao mesmo tempo ética e epistêmica, é politicamente relevante dar à luz "filosofias" insuspeitadas e a salvo da violência dogmática, ou seja, desconstruir o vocabulário hegemônico em seu próprio arcabouço conceitual para revelar novas perspectivas éticas $e$ ontológicas, inclusive para o próprio conceito do humano $e$, consequentemente, para as disciplinas acadêmicas que se classificam pela etiqueta pluralista de "humanidades" (SODRÉ, 2017, p.15).

Há elementos potentes para acreditarmos numa transformação dessa realidade através das fissuras decoloniais que podem ser empreendidas, com criatividade, através de brechas institucionais, em atuações micropolíticas. Mas para isso a autocrítica filosófica é um pressuposto. Como fazer, então, após assumir esse compromisso com a auto- crítica? A proposta aqui é trabalhar nas brechas institucionais, criando fissuras, tensionando o status quo, muitas vezes de dentro mesmo das instituições, pois não nos parece estratégico romper com elas, muito menos agir no sentido de sua aniquilação. E assim, fazer o enfrentamento no sentido de alterar o quadro de ausência ou precária presença de corporalidades não masculinas, não brancas, não heteronormativas nas instituições de ensino, nas publicações, nos eventos acadêmicos, nas bancas, nos departamentos, propondo ações afirmativas para ingresso nas pós-graduações e concursos universitários. Retirando-se da zona de conforto das super especializações, buscando conhecimento sobre os saberes outrora invisibilizados, incluindo-os definitivamente em seus planejamentos, currículos, pesquisas, escritas autorais. Desse modo, se assume um compromisso com a decolonialidade, com o projeto da descolonização da filosofia e de suas práticas, que, apostamos, terá impactos profícuos na descolonização das instituições de ensino, com reverberações culturais e sociais. Porém todo processo de descolonização inicia-se com a árdua e corajosa tarefa de descolonizar-se a si mesma/o. Pode soar pretensioso esse projeto, esse desejo, mas não assumir esse compromisso significa, conscientemente, ser agente da manutenção e do acirramento da colonialidade que está posta, com toda a violência já explicitada. Aqui as palavras de Angela Davis surgem como um farol:

Nós tecíamos sonhos de um mundo melhor - sem racismo, sem injustiças econômicas, sem guerras. Nós imaginávamos um futuro mais humano (...). Agora é a vez de vocês imaginarem um futuro mais humano - um 
futuro de justiça, igualdade e paz. $\mathrm{E}$ se vocês desejarem realizar seus sonhos, que continuam sendo os sonhos da minha geração, também devem se levantar e falar abertamente contra a guerra, contra a falta de empregos e contra o racismo (2017, p.146).

\section{Criando fissuras decoloniais}

A escola e a universidade podem ser resumidas aos traços da colonialidade? Afirmamos esses espaços ensinantes como locus privilegiado para a convivência política, uma vez que promovem o encontro dos corpos no espaço comum. Acreditamos na potência de seu vir a ser, desde que sejam assumidos compromissos com a descolonização de seus saberes e práticas nesse caminho de reinventar-se, na criação de porvires. Em especial nas grandes cidades de um mundo cada vez mais individualista, atomizado, no qual crianças e jovens perdem a cada dia o senso de integração comunitária e os encontros são mais tecnológicos do que corporais - computador, celular, tablet. Nesse contexto, talvez a escola seja o que ainda resta de oportunidade para a convivência na diversidade, para o encontro com o outro, para a socialização, indo além da família nuclear, que não traz a experiência da diferença e que se restringe ao espaço privado, o que nos faz temer profundamente qualquer proposta de homeschooling. Além de ser necessário pontuar, ainda, que, em meio à sobreposição de carências e intersecção de opressões, sabe-se lá como tem se (des)estruturado as famílias subalternizadas em tempos de aprofundamento da recessão econômica e de políticas anti-democráticas e inigualitárias.

Pensamos ser possível propiciar nesses espaços coletivos de produção de conhe- cimento, como a escola e a universidade, simultaneamente, um caminho pessoal para o desenvolvimento de conhecimentos significativos e aprimoramento de si (epistêmico, evidentemente, mas também ético, político, estético), como caminhos para o fomento de coletivos de enunciação. Essas atuações na escola, na universidade, entendidas enquanto microcosmos da convivência política são laboratórios para as atuações no espaço público, no jogo democrático, quando fundamentadas nos valores da interculturalidade, da diversidade, do respeito à diferença, que sustentam a democracia. Esperamos que, através de uma teia de fissuras decoloniais nos currículos e práticas, seja possível fomentar a experiência da coletividade nas turmas, na militância (em grêmios, diretórios e centros acadêmicos e estudantis), nos grupos de amigos e colegas para a realização de exercícios filosóficos e avaliações colaborativas, pesquisas e escritas compartilhadas, em experiências de organização de eventos plurais para o encontro de múltiplas corporalidades. Merecem destaque as atuações nos coletivos que se estruturam nas brechas institucionais a partir de recortes raciais, de gênero, classe, religião, sexualidade, entre outros, que atuam tanto na troca e no suporte, visando a cura pessoal, emocional e psicológica, como também alimentando processos de cura estrutural. É crucial a importância dessas coletividades, da convivência e da socialização no compartilhamento das aprendizagens e saberes, erros e dificuldades, opressões e resistências, superações e enfrentamentos inerentes ao campo da educação, campo ao qual nenhum/a docente está eximida/o de atuar, seja do ensino superior ou da educação básica. 
Um dos antípodas da concepção de escola colonizadora, que infelizmente ainda predomina, pode ser identificado no legado afro-indígena que constitui muito da cultura brasileira e com o qual podemos aprender elementos capazes de esgarçar $e$ fissurar esse modelo de escola entendido como herança da colonialidade que aprisiona, até os dias de hoje, a diversidade de saberes, ancestrais, ligados à natureza, ao corpo, à sensibilidade, intuição, afetividade. Porém, as instituições de ensino, tais como a escola e a universidade, tenderam, ao longo de sua história, a desvalorizar as experiências e os saberes produzidos por corporalidades afrodiaspóricas e indígenas, deixando-as do lado de fora dos currículos, sob a classificação de 'marginais', com escusas como ausência de objetividade, universalidade ou sistematização. Sem abrir mão da escola, viemos aqui nos perguntar em quê e o quanto práticas de ensino e currículos afro-indígenareferenciadas podem contribuir para a necessária tarefa de reinventar as instituições de ensino. E, dessa maneira, criar fissuras, abrindo fendas para que elas sejam alimentadas, estimuladas, fertilizadas por saberes práticos, ligados à natureza, pelo quilombismo e a pedagogia do terreiro, na criação de espaços de aquilombamento, de cultivo desse nós, sem o qual nenhuma individualidade pode sequer existir - ubuntu. "Eu sou porque nós somos" - ainda que a teia de significados para ubuntu seja muito mais complexa. O nós inclui aqui tudo o que a ciência ocidental denomina como os reinos vegetal, animal, mineral e os demais seres - todos vivos e igualmente necessários à harmonia do todo.
Como nos ensina Ailton Krenak, o equívoco já está no antropocentrismo, pois não há cisão entre ser humano e natureza.

Fomos nos desligando desse organismo de que somos parte, a Terra, e passamos a pensar que ele é uma coisa e nós, outra: a Terra e a humanidade. Eu não percebo onde tem alguma coisa quer não seja natureza. Tudo é natureza. O cosmos é natureza. Tudo em que eu consigo pensar é natureza (KRENAK, 2019, p.9).

Assim, é necessário abrimos brechas e nos esvaziar, no sentido de desaprender o modo hegemônico ocidentalizado, gerando espaço para conseguirmos (re)aprender a partir dessa e de outras fontes de riqueza intercultural existentes na própria cultura brasileira, afro-diaspórica e pindorâmica, presente em nossa ancestralidade, possível de resgate e capaz de nos reconectar.

Como colocar essa reflexão e crítica em prática? $\mathrm{Na}$ perspectiva que aqui afirmamos, precisamos tensionar e propor outras estratégias de ensino, didáticas e metodologias que integrem os saberes, retirandoos do isolamento das gavetas das super especializações, valorizando a dimensão da prática, o sentir-pensar, a integração com a natureza, os fazeres e saberes coletivos que desenvolvem a escuta, a fala argumentativa, a negociação horizontal entre pares, tão caros ao modus operandi democrático. Como também se faz necessário provocar enfrentamentos no campo dos recortes curriculares, sempre em disputa, alterando o jogo de forças daquilo que fica dentro ou fora dos currículos, programas e planejamentos, aquilo em que se coloca foco ou o que é borrado, 
apagado, silenciado, sedimentando o caminho para a superação do epistemicídio.

Brasil, meu nego
Deixa eu te contar
A história que a história não conta
O avesso do mesmo lugar
Na luta é que a gente se encontra
Brasil, meu dengo
A Mangueira chegou
Com versos que o livro apagou
Desde 1500 tem mais invasão do
que descobrimento
Tem sangue retinto pisado
Atrás do herói emoldurado
Mulheres, tamoios, mulatos
Eu quero um país que não está no
retrato (...).
(Histórias para ninar gente grande,
G.R.E.S. Estação Primeira de Man-
gueira, samba-enredo de 2019)

Podemos listar aqui algumas possibilidades práticas com o objetivo de apresentar exemplos inspiradores, ainda que sem nenhuma pretensão prescritiva: i) aprender, sobre a linguagem, com a filósofa e antropóloga brasileira, Lélia Gonzalez, que aqui no Brasil falamos mesmo é pretoguês, uma vez que já incorporamos em nossa fala, totalmente brasileira, inúmeros elementos vocativos, rítmicos, fonéticos de variadas línguas do tronco bantu, como o quimbundo e o quicongo; ii) que melhor seria se denominássemos nosso território como Améfrica ladina, pois, já nos alertara essa mesma intelectual, militante fundadora do MNU (movimento negro unificado) e do coletivo de mulheres negras Nzinga: o termo América está carregado do simbólico estadunidense, que não nos pertence, e latino foi um termo cunhado por Napoleão para reivindicar e justificar seu direito às colônias ibéricas, em seus deva- neios de dominação global do mundo (GONZALEZ, 2018); iii) ensinar a xenofilia, inerente a muitos povos e culturas indígenas, africanas e afrodiaspóricas, que significa acolhimento, amor, amizade pelo diferente, pelo outro que nos completa, atribuindo sentido às nossas vidas, diferentemente da tradição européia, globalizada enquanto padrão hegemônico, que baseia-se no oposto, na xenofobia, o que tem gerado, historicamente, um mundo de muros e apartações; iv) exercitar práticas agroecológicas de cultivo e cuidado da natureza, visando a soberania alimentar e a manutenção da vida dos seres (humanos e não-humanos), sua equidade de direitos contra o especismo, superando o ecocídio, sem poluir terras, rios, mares, $e$ todo o exuberante legado cultural ancestral de preservação da natureza presente nas Améfricas, como traços de uma outra relação com o mundo; v) praticar na universidade e na escola escritas baseadas em biografias, narrativas de si, escrevivências (conceito criado pela escritora Conceição Evaristo [2005], que também pode servir como metodologia fértil), que incluem a vida, o corpo, os afetos, as subjetividades na produção textual (habilidade intrínseca ao filosofar $e$ ao ensinar a filosofar) - levando para o interior da escola esses elementos que costumam ser negligenciados no modelo de escola eurocentrado, preocupado com a normalização dos corpos; vi) especificamente no ensino de filosofia, fissurar e inocular no cânone filosófico definitivamente as filosofias africanas, latinoamericanas, orientais, dos povos indígenas, afirmar e valorizar as filósofas mulheres e sua produção intelectual, as filosofias afro-diaspóricas, brasileiras, incluindo assim, de fato, nossas/os estudantes e suas corpora- 
lidades no saber-fazer filosófico, não permitindo que se alienem de si mesmos ao adotar modelos e valores "globalizados" que são, na prática, a universalização de valores eurocêntricos e mercantilistas; vii) na área das humanidades, valorizar experiências coletivas de convivência comunitária, esgarçando o paradigma político excludente do contratosocial, mas que parece absoluto, com a apresentação de uma diversidade de outras experiências: como, por ex., pesquisar e ensinar o quilombismo, os aldeamentos e aquilombamentos, como outros modos possíveis de existir coletivamente, indo muito além de um contrato social que já surge colocando a todas/os que habitam as geografias e corporalidades "outras" à margem do humano $e$ de seus direitos.

$\mathrm{O}$ primeiro estado livre de todo o continente americano surgiu no Brasil e foi criado pelos negros que, resistindo à escravidão, se dirigiram para o sul da capitania de Pernambuco, hoje estado de Alagoas, a fim de criar uma sociedade livre $e$ igualitária, uma sociedade alternativa onde negros, índios e brancos pobres viviam no maior respeito, proprietários da terra e senhores do produto do seu trabalho. Palmares é um exemplo livre e típico de uma nacionalidade brasileira que ainda está por se constituir, nacionalidade essa onde negros, brancos irmãos [estejam], juntos nesse momento, para que esse país se transforme efetivamente numa democracia." (Lélia Gonzalez na manifestação em homenagem a Zumbi dos Palmares, em 20 de novembro de 1988).

Não é coincidência que estejamos até hoje, em nossos territórios subalternizados, reivindicando os direitos humanos (ou do humano), reivindicando sermos incluídas/os nessa humanidade. Como nos convida a filósofa brasileira afro-diaspórica Lélia González, há mais de quarenta anos, juntamente com os movimentos negro, indígena, lgbtqi+, feministas, para empreendermos uma repactuação em nossa sociedade, com reparações que nos permitam, efetivamente, curar e superar a ferida colonial que cinde $e$ dilacera, ainda que as conseqüências sejam bastante desiguais para os diferentes grupos identitários que compõem a nossa cultura.

\section{Alinhavando considerações finais}

Os exemplos podem se desdobrar infinitamente se nós, que atuamos no ensino da filosofia, abrirmos nossa criatividade para, através de múltiplas fissuras micropolíticas, reinventar a filosofia, seu ensino, a escola, a universidade, tecendo outras tramas e, por reverberação, tramando outros modos de viver e estar no mundo. Fortalecendo estudos, pesquisas, ações que visem, tanto à crítica ao padrão da colonialidade nos espaços de ensino, currículos e metodologias, quanto, propositivamente, afirmem as práticas e relatos que disseminam experiências e projetos de educação decolonial, antirracista, antissexista. Assumindo um compromisso com a reinvenção, no sentido de criar condições para que esses espaços formais de produção de conhecimento, em especial quando públicos, possam servir de alicerce para a convivência democrática, potencializadora da vida comunitária, em sua diversidade intrínseca. Isso só poderá ocorrer através de recortes curriculares que não silenciem, nem invisibilizem a produção $e$ os saberes das mulheres, de indígenas, afro-brasileiros, das classes sociais mais empobrecidas, das popu- 
lações tradicionais, ribeirinhas/os, agricultoras/es, comunidades de terreiro, quilombolas, aliado ao exercício cotidiano de práticas de ensino-aprendizagem descolonizadoras acolhedoras, afetivas, curativas. Termino evocando as sábias palavras de Elza Soares, em sua obra de arte intitulada Deus é mulher, na música Exu nas escolas.

Exu nas escolas $[3 \mathrm{x}]$

Exu no recreio

Não é show da Xuxa

Exu brasileiro

Exu nas escolas

Exu nigeriano

Exu nas escolas

E a prova do ano

É tomar de volta

A alcunha roubada

De um deus iorubano

Exu nas escolas (ê-ê-exu) [4x]

Estou vivendo como um mero mor-

tal profissional

Percebendo que às vezes não dá pra ser didático

Tendo que quebrar o tabu e os costumes

frágeis das crenças limitantes

Mesmo pisando firme em chão de

giz

De dentro pra fora da escola

é fácil aderir a uma ética e uma ótica

Presa em uma enciclopédia de ilu-

sões bem selecionadas

E contadas só por quem vence

Pois acredito que até o próprio Cristo

era um pouco mais crítico em rela-

ção a tudo isso

E o que as crianças estão pensando?

Quais são os recados que as baleias

têm para dar a nós

seres humanos, antes que o mar vire uma gosma?

Cuide bem do seu Tcheru

$\mathrm{Na}$ aula de hoje veremos exu

Voando em tsuru

Entre a boca de quem assopra

$e$ o nariz de quem recebe o tsunu

As escolas se transformaram em centros ecumênicos

Exu te ama e ele também está com

fome

Porque as merendas foram desvia-

das novamente

Num país laico, temos a imagem de

César na cédula

e um "Deus seja louvado"

As bancadas e os lacaios do Estado

Se Jesus Cristo tivesse morrido nos

dias de hoje com ética

Em toda casa, ao invés de uma cruz teria uma cadeira elétrica

(Elza Soares)

De acordo com a cosmologia e a ontologia africana e afro-diaspórica do candomblé, Exu (ou Nzila) é responsável pelas trocas, pela comunicação, entendido como o próprio movimento dinamizador da existência (SODRÉ, 2017). Salve, salve, Exu, Nzila! Que essa energia abra os caminhos e nos fortaleça no sentido da mudança, nos dando coragem e força para empreender as fissuras capazes de transformar o estabelecido - na filosofia, na educação, no ensino, nas escolas e universidades e, por reverberação, na vida. Laroyê, mojubá! 


\section{Referências}

ARAÚJO, C. "Quatorze anos de desigualdade: mulheres na carreira acadêmica de Filosofia no Brasil entre 2004 e 2017". Cadernos de Filosofia Alemã: Crítica e Modernidade, 24(1), 13-33, 2019. https://doi.org/10.11606/issn.2318- 9800.v24i1p13-33

BANIWA, G. (2006). O Índio Brasileiro: o que você precisa saber sobre os povos indígenas no Brasil de hoje. Brasília, DF: Ministério da Educação. (Coleção Educação para Todos).

BENTO, M. "Branqueamento e branquitude no Brasil", em: Psicologia social do racismo estudos sobre branquitude e branqueamento no Brasil. CARONE, Iray; BENTO, Maria Aparecida (org.) Petrópolis/RJ: Vozes, 2002.

DAVIS, A. Mulheres, cultura e política. São Paulo: Boitempo, 2017.

DE OTO, Al; CATELLI, L. "Sobre colonialismo interno y subjetividad: notas para un debate". Tabula Rasa. Bogotá - Colombia, No.28, enero-junio 2018, p. 229-255. Doi: https://doi.org/10.25058/20112742.n28.10

DOMÊNICO, D; MIRANDA, T.; MAMA; BOLA, M; OLIVEIRA, R; FIRMINO, D; CUÍCA, M; MÁXIMO, L. Histórias para ninar gente grande. Rio de janeiro: samba-enredo da G.R.E.S. Estação Primeira de MANGUEIRA, 2019. Disponível em: https://www.youtube.com/watch?v= JMSBisBYhOE

DUSSEL, E. "Europa, modernidad y eurocentrismo", em: LANDER, Edgardo (coord). La colonialidaddel saber: eurocentrismo y cienciassociales, perspectivas latino-americanas. Buenos Aires: CLACSO, 2000.

EVARISTO, C. "Gênero e etnia: uma escre(vivência) de dupla face." Em: MOREIRA, Nadilza Martins de Barros; SCHNEIDER, Liane (Org.). Mulheres no mundo: etnia, marginalidade e diáspora. João Pessoa: Ideia /Editora Universitária UFPB, 2005.

FANON, F. Pele negra, máscaras brancas. Salvador: EDUFBA, 2008.

FOUCAULT, M. Vigiar e punir: nascimento da prisão. Petrópolis/RJ: Vozes, 1987.

FREIRE, P. Pedagogia da autonomia: saberes necessários à prática educativa. São Paulo: Paz e Terra, 1996.

GOMES, N. O movimento negro educador: saberes construídos nas lutas por emancipação. Petrópolis: Vozes, 2017.

GONZALEZ, L. Primavera para as rosas negras. Lélia Gonzalez em primeira pessoa... São Paulo: UCPA/Diáspora Africana, 2018.

Manifestação em homenagem a Zumbi dos Palmares, em 20 de novembro de 1988. Disponível em: https://www.youtube.com/watch?v=BFnvKcsLqJI

GROSFOGEL, R. "A estrutura do conhecimento nas universidades ocidentalizadas: racismo/sexismo epistêmico e os quatro genocídios/epistemicídios do longo século XVI". Revista Sociedade e Estado, volume 31, número 1, Janeiro-Abril/2016. 
HOOKS, B. Ensinando a transgredir: a educação como prática da liberdade. São Paulo: editora WMF/Martins Fontes, 2017.

KAFURENGÁ, Mam'etu (SANTOS, M.) Pedagogia do terreiro: experiências da primeira escola de religião e cultura de matriz africana do baixo sul da Bahia - Escola Caxuté. Simões Filho [BA]: Kalango, 2019.

KILOMBA, Grada. Memórias da plantação. Episódios de racismo cotidiano. Rio de Janeiro: Cobogó, 2019.

KOPENAWA, D; ALBERT, B. A queda do céu: palavras de um xamã yanomami. São Paulo: Companhia das Letras, 2015.

KRENAK, A. Ideias para adiar o fim do mundo. São Paulo: Companhia das Letras, 2019.

LUGONES, María. "Rumo a um feminismo descolonial". Estudos Feministas, Florianópolis, 22(3): p.935-952, set-dez/2014.

MEMMI, A. Retrato do colonizado precedido de Retrato do colonizador. Rio de Janeiro: Civilização Brasileira, 2007.

NOGUERA, R. O ensino de filosofia e a lei 10.639. Rio de Janeiro: Pallas; Biblioteca Nacional, 2014.

QUIJANO, A. "Colonialidade do poder e classificação social". em: SOUZA SANTOS, Boaventura; MENESES, Maria Paula (orgs.). Epistemologias do sul. São Paulo: Cortez, 2010, p.84130.

SOARES, E. "Exú nas escolas", em: Deus é mulher. Disponível em:

https://www.youtube.com/watch?v=Kw9ke8zt7XA

SODRÉ, M. Pensar Nagô. Petrópolis: Vozes, 2017.

WALSH, C. "Interculturalidad crítica, pedagogíadecolonial". Em: VILLA, W.; GRUESO, A. (org.) Diversidad, interculturalidad y construcción de ciudad. Bogotá: Universidad Pedagógica Nacional/Alcadía Mayor, 2008.

Recebido em: $25 / 05 / 2020$

Aprovado em: 22/10/2020 